\title{
Anterior Mediastinal Fat Changes in Idiopathic Pulmonary Fibrosis: A Preliminary Study
}

\author{
Wafaa Ali Hassan*, Eman Abo-Elhamd \\ Chest and Radiology Departments, Assiut University Hospital, Assiut, Egypt

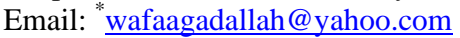

Received December 17, 2013; revised January 17, 2014; accepted January 24, 2014

\begin{abstract}
Copyright (C) 2014 Wafaa Ali Hassan, Eman Abo-Elhamd. This is an open access article distributed under the Creative Commons Attribution License, which permits unrestricted use, distribution, and reproduction in any medium, provided the original work is properly cited. In accordance of the Creative Commons Attribution License all Copyrights (C) 2014 are reserved for SCIRP and the owner of the intellectual property Wafaa Ali Hassan, Eman Abo-Elhamd. All Copyright (C 2014 are guarded by law and by SCIRP as a guardian.
\end{abstract}

\section{ABSTRACT}

Background: The mediastinum is composed primarily of fatty tissue that is surrounded by the lungs bilaterally. There is a lack in the published literature in studying changes in mediastinal fat in idiopathic pulmonary fibrosis (IPF). The purpose of this study was to determine whether the shape and dimensions of the anterior mediastinal fat in patients with IPF are different from that of a normal control group and to correlate the changes with disease severity. Design and Setting: This prospective case control study was done at the chest department of Assiut University Hospital on IPF patients from May 2010-September 2012. A questionnaire containing questions such as age, sex, clinical findings, high resolution computerized tomography (HRCT) score and pulmonary function tests (PFTs) was filled for patients and normal controls. Results: The IPF retrosternal AP dimension was significantly shorter $(p=0.03)$ and the transverse dimension was longer $(p=0.001)$ than that in the normal control group. The convex shape of the anterior mediastinum was predictive of IPF $(p=0.001)$, whereas concave shape was predictive of normal controls $(p=0.001)$. The change in anteroposterior diameter (AP) and transverse diameters showed significant correlation with the changes in FVC, DLCO and HRCT score. Conclusions: IPF patients had reduced retrosternal AP and increased transverse dimensions than those of the controls with convex shape of their anterior mediastinal fat. Changes in anterior mediastinal fat dimensions are correlated with lower FVC, DLCO and higher HRCT score. A larger sample size, better multicenteric study is needed to confirm the results of this study.

\section{KEYWORDS}

Mediastinum; Fat; Idiopathic Pulmonary Fibrosis; CT

\section{Introduction}

The mediastinum is composed primarily of fatty tissue that is surrounded by the lungs bilaterally [1]. Therefore, the shape of the mediastinum readily adapts to the changes in lung pathology [2]. Mediastinal changes have been reported in various pathologic conditions. In patients with a treated neoplasm, any mediastinal bulge that develops suggests extension or recurrence of tumor [3]. However, if the patient has been irradiated, mediastinal widening may occur due to adjacent lung scarring with subsequent retraction of mediastinal pleura laterally. Other causes of lung scarring can similarly widen the

\footnotetext{
"Corresponding author.
}

mediastinum. Mediastinal widening can be seen in idiopathic pulmonary fibrosis (IPF) [4]. Unfortunately, proper description of the shape of anterior mediastinal fat in IPF is not widely studied [4]. Moreover, to the best of our knowledge, its relation to PFTs and HRCT score has never been assigned. The purpose of this study was to describe the shape and dimensions of the anterior mediastinal fat in patients with IPF in comparison to normal control group utilizing HRCT scan and PFTs.

\section{Patients and Methods}

This prospective case-control study was conducted at the Chest department of Assiut University Hospital, Egypt 
on IPF patients from May 2010-September 2012. IPF (UIP) was diagnosed in 46 patients by a combination of the criteria of the American Thoracic Society and European Respiratory Society (ATS/ERS) [5] without open lung biopsy. Forty age and sex matched individuals who had no abnormal lesions on HRCT or PFTs were selected as controls. To exclude other factors that might change the shape of the anterior mediastinal fat, patients with history of tuberculosis, empyema, connective tissue diseases, exposure to organic or inorganic dust or toxic fumes, Cushing disease, asthma or any other diseases requiring steroid medication were excluded from the study population. Patients who had been treated with steroids before HRCT were excluded for the same reason [4]. Our Ethics institutional review board approved this study.

\section{High-Resolution CT}

High-Resolution CT was performed in all patients with a scanner (GE medical systems). The scans were $1 \mathrm{~mm}$ collimation at 1-mm intervals from the apices to the lung bases, 0.5 -second gantry rotation time, $120 \mathrm{kVp}$, and 130 mAs during maximum inspiration with the patient supine and extending from lung apex to diaphragm. The shape of the anterior mediastinal fat was categorized concave, flat or convex at the level of the main pulmonary trunk. The anteroposterior (AP) (from the posterior wall of the sternum to the anterior wall of the ascending aorta) and transverse dimensions (the width of the posterior wall of the sternum in contact with the anterior mediastinal fat) at the level of the main pulmonary trunk were also measured [4].

\subsection{Scoring of HRCT Findings}

The thin-section CT findings were graded on a scale of 1 - 6 on the basis of the classification system previously described [6,7]: score of 1 , normal attenuation; score of 2 , ground-glass attenuation; score of 3 , consolidation; score of 4 , ground-glass attenuation with traction bronchiolectasis or bronchiectasis; score of 5 , consolidation with traction bronchiolectasis or bronchiectasis; and score of 6 , honeycombing. The presence of each of these six abnormalities was assessed independently in three (upper, middle, and lower) zones of each lung. The extent of each abnormality was determined by visually estimating the percentage (to the nearest 10\%) of the affected lung parenchyma in each zone. The abnormality score for each zone was calculated by multiplying the percentage area by the point value (the score of $1-6$ ) $[8,9]$. The six zone scores were averaged to determine the total score for each abnormality in each patient. The overall HRCT score for each patient was obtained by adding the six averaged scores [10-13].

\subsection{Statistical Analysis}

All the analysis was performed with SPSS System software (version 14.0). The shapes of the anterior mediastinal fat in the IPF and control groups were compared using the Chi-square test. Correlations of FVC, Dlco and HRCT score with AP and transverse diameters of anterior mediastinal fat were done using Pearson's correlation coefficient. $\mathrm{P}$ value of equal or less than 0.05 was considered to indicate statistically significant differences.

\section{Results}

Comparisons of the 46 matched study subjects are summarized in Table 1. No significant differences in age, weight and BMI were observed among the study and normal control groups. The retrosternal AP dimension and transverse dimension of the anterior mediastinal fat were significantly different among the two groups. The IPF retrosternal AP dimension was significantly shorter $(p=0.03)$ and the transverse dimension was significantly longer $(p=0.001)$ (Figure 1 ) than that in the normal control group (Figure 2). The shapes of anterior mediastinum were significantly different among the groups (Table 2). The convex shape of the anterior mediastinum was predictive of IPF ( $p=0.001)$, whereas concave shape was predictive of normal controls $(p=0.001)$. Correlation between the changes in AP and transverse diameters of anterior mediastinal fat and the changes in the extent of pulmonary function and HRCT score is shown in Table 3. The change in AP and transverse diameters showed significant correlation with the changes

Table 1. Shapes of anterior mediastinum in IPF and normal control group.

\begin{tabular}{cccc}
\hline & Control group $(\mathrm{n}=40)$ & $\mathrm{IPF}(\mathrm{n}=46)$ & $\mathrm{p}$ value \\
\hline Flat & $1(2.5 \%)$ & $3(6.5 \%)$ & 0.865 \\
Concave & $39(97.5 \%)$ & 0 & 0.001 \\
Convex & 0 & $43(93.5 \%)$ & 0.001 \\
\hline
\end{tabular}

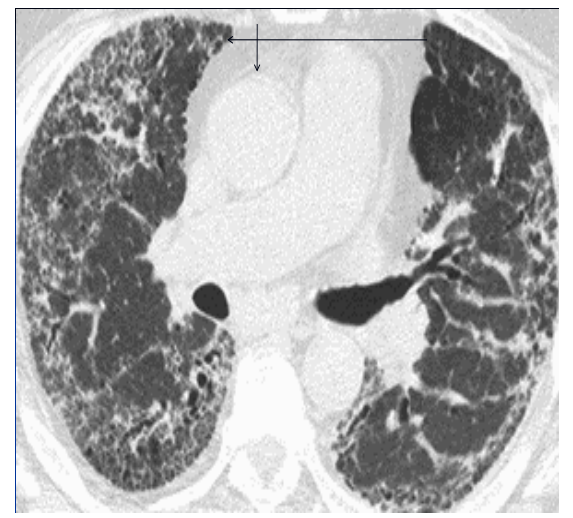

Figure 1. Convex shape of the anterior mediastinum in the IPF group. 


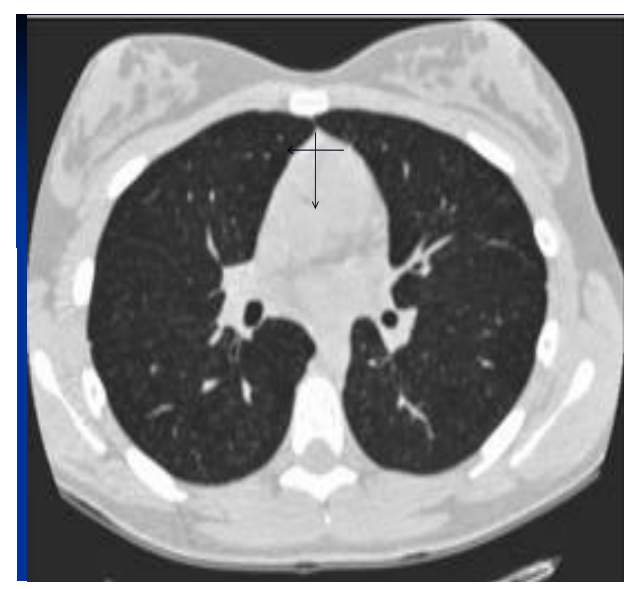

Figure 2. Concave shape of the anterior mediastinum in the normal control group.

Table 2. AP and transverse dimensions in IPF and normal control group.

\begin{tabular}{cccc}
\hline & $\begin{array}{c}\text { Control group } \\
(\mathrm{n}=46)\end{array}$ & $\begin{array}{c}\text { IPF group } \\
(\mathrm{n}=46)\end{array}$ & p value \\
\hline Weight $(\mathrm{kg})$ & $71 \pm 12.2$ & $68 \pm 11.3$ & 0.310 \\
BMI $\left(\mathrm{kg} / \mathrm{m}^{2}\right)$ & $23.5 \pm 2.5$ & $25 \pm 1.6$ & 0.65 \\
Tve diameter $(\mathrm{mm})$ & $9.6 \pm 6.3$ & $24.3 \pm 4.5$ & 0.001 \\
AP diameter $(\mathrm{mm})$ & $17.8 \pm 5.2$ & $8.3 \pm 3.3$ & 0.03 \\
\hline
\end{tabular}

Table 3. Correlation between the changes in the diameters of anterior mediastinal fat with pulmonary Function and HRCT score in IPF group.

\begin{tabular}{cccc}
\hline & FVC & DLco & HRCT score \\
\hline \multirow{2}{*}{ Tve diameter } & $\mathrm{r}=-0.723$, & $\mathrm{r}=-0.236$, & $\mathrm{r}=0.453$, \\
& $\mathrm{p}=0.001$ & $\mathrm{p}=0.05$ & $\mathrm{p}=0.021$ \\
AP diameter & $\mathrm{r}=401$, & $\mathrm{r}=0.016$, & $\mathrm{r}=-0.323$, \\
& $\mathrm{p}=0.001$ & $\mathrm{p}=0.896$ & $\mathrm{p}=0.014$ \\
\hline
\end{tabular}

in FVC $(r=-0.723, p=0.001)$, but only the change in transverse diameter was correlated with the change in $\operatorname{DLCO}(\mathrm{r}=-0.236, \mathrm{p}=0.05)$.

The HRCT score showed significant correlation with reduced AP diameter $(\mathrm{r}=-0.323, \mathrm{p}=0.014)$ and also with increased transverse diameter $(r=0.453$, $p=0.021)$ of anterior mediastinal fat.

\section{Discussion}

Although mediastinal widening in idiopathic pulmonary fibrosis has been previously described, there were limited data on objective CT analysis on anterior mediastinal fat in idiopathic pulmonary fibrosis [14,15]. Mediastinal widening can be the result of steroid medication or fibrous scarring $[15,16]$. However, because we excluded the patients who had previously received corticosteroid medications, its effect could be ignored in the present study.
According to the results of our study, IPF group was associated with a significantly reduced AP dimension and an increased transverse dimension with the resultant convex shape of the anterior mediastinum as compared with control group. In IPF patients, subpleural fibrosis and honeycombing change with volume loss usually occurs at the periphery of the lung base and could result in widening of the transverse dimension and shortening of the AP dimension of the adjacent anterior mediastinum [15].

Toei et al. [17] analyzed the changes in the amounts and distributions of the anterior mediastinal fat after left upper lobectomy, as determined by CT. The postoperative anterior mediastinal fat distribution was distinctly changed with marked increase from the aortic arch to the main pulmonary arterial level. Likewise, in our study, loss of volume of both lower basal lungs due to the fibrosis in IPF might cause a redistribution of fat tissues and the anterior mediastinal shape changes.

The convex shape of the anterior mediastinum was due to a reduced AP dimension, and an increased transverse dimension. Though the evaluation of the mediastinal shape is not presented as a definitive diagnostic tool for any specific disease entity that causes pulmonary fibrosis, it could provide an easy way of observing the overall fibrosis in the lung parenchyma $[18,19]$. To the best of our knowledge, the correlation between the diameters of anterior mediastinal fat and severity of IPF was not wellstudied. We found a significant correlation of increased transverse diameter with reduced FVC and DLCO. Higher HRCT score was also correlated with reduced AP diameter and increased transverse diameter. A larger study is needed to confirm our results.

There were limitations to our study, the small sample size and the presence of other conditions such as, chest wall movement and the phase of respiration that might have affected the measurement of the anterior mediastinal fat, although inspiratory HRCT scans were performed.

In conclusion, IPF patients had different retrosternal AP and transverse dimensions from those of the normal individuals with a tendency to have a convex shape of their anterior mediastinal fat. More increase in transverse diameter and reduction of AP diameter were observed among cases with lower FVC, DLCO and higher HRCT score. A larger sample size, better multicenteric study is needed to confirm the results of this study.

\section{REFERENCES}

[1] L. Cheung, J. Gertow, O. Werngren, L. Folkersen, N. Petrovic, J. Nedergaard, A. Franco-Cereceda, P. Eriksson, and R. Fisher, "Human Mediastinal Adipose Tissue Displays Certain Characteristics of Brown Fat," Nutrition \& Diabetes, Vol. 3, No. 5, 2013, p. 66. http://dx.doi.org/10.1038/nutd.2013.6 
[2] E. R. Fisher and J. D. Godwin, "Extrapleural Fat Collections: Pseudotumors and Other Confusing Manifestations," American Journal of Roentgenology, Vol. 161, No. 1, 1993, pp. 47-52.

http://dx.doi.org/10.2214/ajr.161.1.8517319

[3] P. Macchiarini and H. Ostertag, "Uncommon Primary Mediastinal Tumours,” The Lancet Oncology, Vol. 5, No. 2, 2004, pp. 107-118. http://dx.doi.org/10.1016/S1470-2045(04)01385-3

[4] C. H. Lee, H. J. Lee, K. R. Son, E. J. Chun, K. Y. Lim, J. M. Goo, J. G. Im, J. N. Heo and J. W. Song, "CT Analysis of the Anterior Mediastinum in Idiopathic Pulmonary Fibrosis and Nonspecific Interstitial Pneumonia,” Korean Journal of Radiology, Vol. 7, No. 3, 2006, pp. 173-179. http://dx.doi.org/10.3348/kjr.2006.7.3.173

[5] G. Raghu, H. R. Collard, J. J. Egan, et al., “An Official ATS/ERS/JRS/ALAT Statement: Idiopathic Pulmonary Fibrosis: Evidence-Based Guidelines for Diagnosis and Management," American Journal of Respiratory and Critical Care Medicine, Vol. 183, No. 6, 2011, pp. 788-824. http://dx.doi.org/10.1164/rccm.2009-040GL

[6] T. E. Hartman, S. J. Swensen, D. M. Hansell, T. V. Colby, J. L. Myers, H. D. Tazelaar, et al., "Nonspecific Interstitial Pneumonia: Variable Appearance at High-Resolution Chest CT,” Radiology, Vol. 217, No. 3, 2000, pp. 701705. http://dx.doi.org/10.1148/radiology.217.3.r00nv31701

[7] S. Hiromitsu, J. Takeshi, I. Kazuya, T. Hiroyuki, et al., "Usual Interstitial Pneumonia and Chronic Idiopathic Interstitial Pneumonia: Analysis of CT Appearance in 92 Patients,” Radiology, Vol. 241, No. 1, 2006, pp. 258-266.

[8] Z. D. Niil, F. C. Gilchrist, A. G. Nicholson, D. M. Hansell, J. Harris, T. V. Colby, et al., "A Histologic pattern of Nonspecific Interstitial Pneumonia Is Associated with a Better Prognosis Than Usual Interstitial Pneumonia in Patients with Cryptogenic Fibrosing Alveolitis," American Journal of Respiratory and Critical Care Medicine, Vol. 160, No. 3, 1999, pp. 899-905. http://dx.doi.org/10.1164/ajrccm.160.3.9903021

[9] K. R. Flaherty, W. D. Travis, T. V. Colby, G. B. Toews, E. A. Kazerooni, B. H. Gross, et al., "Histologic Variability in Usual and Nonspecific Interstitial Pneumonias," American Journal of Respiratory and Critical Care Medicine, Vol. 164, No. 9, 2001, pp. 1722-1727. http://dx.doi.org/10.1164/ajrccm.164.9.2103074

[10] W. D. Travis, K. Matsui, J. Moss and V. J. Ferrans, "Idiopathic Nonspecific Interstitial Pneumonia: Prognostic Significance of Cellular and Fibrosing Patterns: Sur- vival Comparison with Usual Interstitial Pneumonia and Desquamative Interstitial Pneumonia," The American Journal of Surgical Pathology, Vol. 24, 2000, pp. 19-33. http://dx.doi.org/10.1097/00000478-200001000-00003

[11] Y. J. Jeong, K. S. Lee, N. L. Müller, M. P. Chung, M. J. Chung, J. Han, et al., "Usual Interstitial Pneumonia and Non-Specific Interstitial Pneumonia: Serial Thin-Section CT Findings Correlated with Pulmonary Function,” Korean Journal of Radiology, Vol. 6, No. 3, 2005, pp. 143152. http://dx.doi.org/10.3348/kjr.2005.6.3.143

[12] A. C. Best, A. M. Lynch, C. M. Bozic, D. Miller, G. K. Grunwald and D. A. Lynch, "Quantitative CT Indexes in Idiopathic Pulmonary Fibrosis: Relationship with Physiologic Impairment,” Radiology, Vol. 228, No. 2, 2003, pp. 407-414. http://dx.doi.org/10.1148/radiol.2282020274

[13] N. L. Müller, C. A. Staples, R. R. Miller, S. Vedal, W. M. Thurlbeck and D. N. Ostrow, "Disease Activity in Idiopathic Pulmonary Fibrosis: CT and Pathologic Correlation,” Radiology, Vol. 165, 1987, pp. 731-734.

[14] L. Agnaldo, C. Domenico, M. Roberto, L. Pedro and J. José, "Severity Classification for Idiopathic Pulmonary Fibrosis by Using Fuzzy Logic,” Clinics (Sao Paulo), Vol. 66, No. 6, 2011, pp. 1015-1019. http://dx.doi.org/10.1590/S1807-59322011000600016

[15] L. Michele, H. Marvin, M. D. Chasen, F. Reginald and Munden, "Imaging of the Mediastinum in Oncology," $A R$, Vol. 36, No. 1, 2007, pp. 1-2.

[16] H. J. Koerner and D. I. Sun, "Mediastinal Lipomatosis Secondary to Steroid therapy," American Journal of Roentgenology, Vol. 98, No. 2, 1966, pp. 461-464. http://dx.doi.org/10.2214/ajr.98.2.461

[17] H. Toei, M. Furuse, T. Shinozaki and Y. Sohara, "CT Analysis of the Anterior Mediastinal Fat: Before and after Lobectomy,” Nippon Igaku Hoshasen Gakkai Zasshi, Vol. 57, No. 8, 1997, pp. 493-498.

[18] T. Johkoh, N. L. Müller, Y. Cartier, P. V. Kavanagh, T. E. Hartman, M. Akira, et al., "Idiopathic Interstitial Pneumonias: Diagnostic Accuracy of Thin-Section CT in 129 Patients,” Radiology, Vol. 211, No. 3, 1999, pp. 555-560. http://dx.doi.org/10.1148/radiology.211.2.r99ma01555

[19] S. L. MacDonald, M. B. Rubens, D. M. Hansell, S. J. Copley, S. R. Desai, R. M. du Bois, et al., "Nonspecific Interstitial Pneumonia and Usual Interstitial Pneumonia: Comparative Appearances at and Diagnostic Accuracy of Thin-Section CT,” Radiology, Vol. 221, No. 3, 2001, pp. 600-605. http://dx.doi.org/10.1148/radiol.2213010158 